\title{
Representações da paisagem acústica de Macau na narrativa “Min-Pau-Lou" (1998), de Ana Maria Amaro
}

Rogério Miguel Puga ${ }^{1}$

Resumo: O presente artigo analisa a imagem acústica (soundscape), figuras-tipo da Macau do início da segunda metade do século $\mathrm{XX}$, bem como elementos etnográficos, como o vendedor ambulante, da narrativa "Min-Pau-Lou", inserida na antologia de contosexperiências Aguarelas de Macau 1960-1970: Cenas da Rua e Histórias de Vida. Um Olhar Retrospectivo, um Olhar de Saudade (1998), da antropóloga Ana Maria Amaro.

Palavras-chave: conto; imagem acústica (soundscape); narrativa de cariz etnográfico; Macau; vendedores ambulantes.

A antologia de contos Aguarelas de Macau 1960-1970: Cenas da Rua e Histórias de Vida. Um Olhar Retrospectivo, um Olhar de Saudade (AM), publicada em 1998, pela antropóloga Ana Maria Amaro, revela de que forma o trabalho de campo dá origem a material etnográfico também passível de ser ficcionalizado ou narrado em forma de conto, demonstrando a riqueza cultural, linguística e história de Macau. O território tem sido representado de forma realista na literatura ocidental (PUGA, 2009), e $A M$ inscrevem-se nessa tradição, prestando-se as temáticas da obra a uma leitura em torno da representação de cariz realista das imagens 'etnográficas' e acústicas da urbe pela narradora cuja atitude e olhar se assemelham aos de uma etnógrafa. No presente estudo, analisaremos, de forma representativa no que diz respeito ao resto da obra, a representação da imagem acústica, ou soundscape, do conto com título cantonense "Min-Pau-Lou", termo que, como informa o glossário final, significa 'padeiro' (p. 16).

A Professora Ana Maria Amaro (n. 1929), antropóloga jubilada do ISCSP (Universidade Técnica de Lisboa), é presidente do Instituto Português de Sinologia desde 2007, estudando há mais de 45 anos Macau, tendo publicado dezenas de estudos sobre o território. Os título e subtítulo de $A M$ veiculam a relação pessoal que a autora-narradora tem com o enclave, que não voltou a visitar desde os anos (19)70, preferindo recordar esse espaço nas franjas do Império do Meio tal como o conheceu. Em 1957, Ana Amaro e o marido, oficial miliciano destacado para Macau, viajam, um ano após terem

1 Investigador Auxiliar no Centre for English, Translation and Anglo-Portuguese Studies (CETAPS), da FCSH da Universidade Nova de Lisboa (Portugal), onde também dá aulas. Colaborador do Centro de História de Além-Mar na mesma Faculdade de do Centro de Estudos Comparatistas da Faculdade de Letras da Universidade de Lisboa. E-mail: rogerio_puga@hotmail.com 
casado, para o território chinês sob administração portuguesa no paquete Índia da Companhia Nacional de Navegação (CNN), que então ligava, tal como a Companhia Colonial de Navegação $(\mathrm{CCN})$, o império português através das linhas de África, do Brasil e do Oriente. ${ }^{2}$ De acordo com a autora (BOTAS, 2010 , p. 8), a viagem dura cerca de um mês, e o casal chega à China por altura do tufão Glória. A chegada a Macau “na asa do tufão Glória” é descrita por Ana Maria Amaro como um episódio solitário, pois não havia ninguém à sua espera no Porto Exterior. Os recém-chegados viajam num batelão para terra desde a rada onde o Índia fundeara: "Macau apresentava um aspecto assustador. Árvores arrancadas pela raiz, hortas alagadas, suínos mortos ao longo da estrada e tudo cinzento envolto em neblina.” (BOTAS, 2010, p. 8) É este o contexto em que a autora tem o seu primeiro contacto com a urbe dos anos (19)60-70 que descreve em $A M$, fazendo uso do patois do território lusochinês para distinguir os três grupos "que se ombreavam” em Macau:

[...] os portugueses de Portugal (que comi bem e págá mal) no dizer da terra, os "filhos da terra" e os chineses, uns muito ricos, outros muito pobres refugiados de vários pontos da China que eu conheci nas hortas. Alguns apontamentos encontram-se no meu livro "Aguarelas de Macau" que não é ficcionado apenas tem os nomes das pessoas trocados (BOTAS, 2010, p. 8).

$\mathrm{Na}$ referida entrevista, a autora recorda a obra na qual plasmou diversas visões de Macau ao longo de uma década e que apenas publica simbolicamente em 1998, um ano antes da transição da administração de Macau, destacando dois episódios históricos que ocorreram durante a sua estada no sul da China: pela negativa, os levantamentos dos guardas vermelhos em 1966, descritos no conto "A Guerra do "Chau-min"' (AM, p. 69-71) e, pela positiva, a recuperação do Jardim Lou Lim Yok, cuja destruição a autora ajudou a evitar.

Em 1958 a autora começa a leccionar no Liceu de Macau, e a obra de que nos ocupamos revela o interesse da então professora pela etno-história. Ana M. Amaro licenciou-se em Biologia e Ciências Pedagógicas (1954) e em Antropologia Cultural e Social, sendo esta última a área de estudos em que defendeu a sua tese de doutoramento na Universidade Nova de Lisboa, ainda inédita, sobre Medicina popular de Macau. Foi também no território que

2 O paquete Índia foi construído, juntamente com o Timor, em Inglaterra (Sunderland) pela Bartram
\& Sons, em 1950-51. As linhas regulares de paquetes asseguravam o transporte de militares e de
material de guerra para o Ultramar e faziam cruzeiros (rota do Oriente). O percurso do navio era o
seguinte (algumas paragens eram opcionais): Lisboa, Port Said, Suez, Aden, Singapura, Hong
Kong, Macau, Díli, Singapura, Colombo, Goa, Mormugão, Porto Amélia, Nacala, Beira, Lourenço
Marques, Lobito, Luanda e Lisboa. O Índia foi vendido em Singapura na década de 70 e
renomeado Kim Hog.

56 fragmentum, N. 35, parte I. Laboratório Corpus: UFSM, Out./ Dez. 2012 
começou a sua investigação nas áreas da Fitossistemática e Etnobotânica ao estudar as plantas locais e redigir artigos para publicações locais. O casal regressa a Portugal em 1972 antes do boom económico de Macau e da expansão territorial através de aterros, e a autora confessa que atualmente "a realidade de Macau não é sequer conhecida na sociedade portuguesa e há muito poucas pessoas interessadas em conhecê-la. A maior parte das pessoas interessadas são macaenses ou antigos habitantes de Macau" (BOTAS, 2010, p. 10). A antropóloga tem ainda publicados outros textos de carácter etno-histórico e memorialístico, fruto da sua observação participante no território, como é o caso do artigo "A Velha Aldeia de Mong Há Que Eu Conheci" (Revista de Cultura, n. 35-36, 1998) e que dialogam com o conteúdo de contos como "O Kwái da Montanha Russa” (p. 58-60), que descreve a velha aldeia de Mong Há, onde a autora residiu em Macau.

A estada e o trabalho de campo antropológico da autora permitemlhe recolher as cenas de rua e domesticas de uma Macau desaparecida que escreve nas décadas de 70 do século XX e publicada mais tarde em 1998. As 35 micro-narrativas ou contos que compõem $A M$ apresentam-nos, como o próprio título indica, histórias espaciais e biográficas do tecido multicultural de Macau, sem que, no entanto, as comunidades portuguesa e chinesa se misturem nas ruas. No entanto, sons, cores, aromas e sabores dessas duas culturas fundem-se pelas vielas calcetadas e por entre portas e janelas indiscretas que a narradora abre e mantém abertas para revelar momentos e movimentos típicos da urbe. "Histórias de Vida" detém-se assim sobretudo na paisagem humanizada do território, em pessoas concretas, nos hábitos dos macaenses e nos retratos quotidianos de vidas anónimas observados pela autora. Figuras ou tipos humanos em contexto multicultural observados num dado momento histórico da urbe luso-chinesa são desfamiliarizados quando lhes é atribuído um nome ficcional e as personagens locais são cristalizadas através das narrativas que rentabilizam a etnografia e a história como estratégias literárias.

O conto-experiência (testemunhada) "Min-Pau-Lou" ( $A M$, pp. 14-16) permite à narradora apresentar uma das figuras-tipo mais características do enclave, o vendedor ambulante, mais especificamente o padeiro, com os seus pregões específicos ("Min-Pau!": 'pão'), que, como veremos, fazem parte da paisagem acústica e histórico-cultural de Macau. Os sons dos vários contadores de histórias, dos termos em cantonense ou no crioulo local ( $A M$, p. 59), bem como os pregões de vendedores ambulantes, fazem também parte do tecido urbano e da paisagem antropológica macaense ficcionalizados por Ana Maria Amaro. A antologia cristaliza diversas vozes (já) silenciadas da urbe, sendo esse processo complementado por um outro elemento paratextual, o glossário que acompanha o conto em questão $(A M$, p. 16) e que traduz termos e conceitos culturais da China Meridional, como se de um conjunto de notas de rodapé se 
tratasse. Os glossários que encerram cada aquarela narrativa explicam, definem e traduzem também hábitos, festividades e costumes sínicos, ou seja, explicam a história narrada e permitem ao leitor ter um contacto mais direto e informado com a realidade local, podendo os contos ser classificados como poliglotas e polifónicos ao rentabilizar uma rede diversificada de vozes e focalizações pessoais e culturais. Em $A M$ (p. 17), a cidade ora é labirinto desconhecido, ora é mapa já percorrido e desvendado, e o vendedor faz parte dessa textura cultural e urbana. Como o conto de que nos ocupamos sugere, e Isabel Nunes conclui ao estudar os vendilhões de Macau, esse profissional, "que no seu atarefado dia carrega aos seus ombros o fardo de uma longa tradição" (NUNES, 1998, p. 163), ${ }^{3}$ pauta o pulsar da cidade ${ }^{4}$ com os seus característicos gritos e constitui um quadro típico e uma das mais famosas profissões locais, relacionando-se a sua tarefa com o espaço de manobra reservado à mulher chinesa e macaense, o lar de onde esta pouco sai; e, quando o faz, é sempre coberta pelo dó, a caminho da missa ou da casa de um familiar. Essa reclusão é apresentada noutras obras por Ana Maria Amaro ${ }^{5}$ e também por Luís Gonzaga Gomes ${ }^{6}$ para explicar a enorme importância destes comerciantes itinerantes, factor ao qual podemos juntar o calor e a humidade extremos que se fazem sentir no Verão em Macau, a quase inexistência de lojas na cidade e a segurança do sexo feminino, assim menos exposto ao perigo do desconhecido. Ao longo dos textos como "Min-Pau-Lou" acumulam-se referências aos barulhentos vendedores de metal e de vegetais, bem como aos trilhos por eles utilizados e que ligam Macau à China profunda $(A M$, p. 14-21, 25), de onde é originária a maioria dos habitantes do enclave. O leitor informado reconhece assim no texto de que nos ocupamos os pregões do padeiro ambulante enumerados pela narradora (Mái-kái-ié, Ié-mai-chiu, Chucheong-fan, Mái choi ié; Min-Pau!, $A M$, p. 14-15) e que fazem parte da imagem acústica etno-histórica do enclave luso-chinês.

A narradora descreve as janelas que se abrem ao som dos pregões e a correria do vendedor que carrega, a passo de cule, "duas grandes vitrinas, de

\footnotetext{
${ }^{3}$ Sobre as lojas ambulantes de Macau, vejam-se Rego (1949, p. 94) e Barreira (1994, p. 145-47).

${ }^{4}$ Wenceslau de Moraes (1946, p. 69) descreve o percurso e o horário estratégicos dos vendedores nas ruelas da cidade: "Vendilhões vão passando a todo o instante; vendem flôres, vendem hortaliça e fructas, vendem porco assado, pato assado, comidas [...]. Mas isto passa-se lá fora, em quanto a brisa gelada chicoteia os rostos dos que transitam nas viellas".

5 Amaro (1965, p. 49): "É natural que esta afluência de vendedores ambulantes tenha origem nos clássicos cânones da moral confucionista em que assentava a estrutura familiar chinesa, segundo a qual à mulher de boas famílias, escrava dos mais inconcebíveis preconceitos, não seria lícito sair de casa, pois tal procedimento seria considerado escândalo público".

6 Gomes (1994, p. 137) afirma sobre os "marchantes peripatéticos": "possuindo profundos conhecimentos dos hábitos da população, empiricamente adquiridos e hereditariamente transmitidos através de inúmeras gerações, os vendilhões surgem com matemática precisão, isto é, no momento exacto, em que os seus clientes necessitam da sua particular mercadoria".
} 
três prateleiras... [no] bambu vergado sobre o ombro" (p. 14), um quadro etnográfico da cidade, tal como o desse profissional "sentado sobre os calcanhares" e da empregada chinesa de trança, Á-Fong, que carrega avos de cobre para comprar o pão que escolhe cuidadosamente. Se os residentes e flâneurs 'estudados' pela antropóloga na península de Macau e nas ilhas funcionam como informantes da observadora-participante, os contos adquirem um cariz etnográfico ou antropológico que enriquece a dimensão literária dos mesmos, enquanto a cor local e as dimensões chinesa e macaense da obra nos recordam as palavras de antropólogos como Clifford Geertz (1990, p. 9) ao afirmar que os métodos etnográficos de análise da cultura se aproximam, até certo ponto, da tarefa do crítico literário ao analisar um texto: "sorting out the structures of signification [...] and determining their social ground and import [...]. Doing ethnography is like trying to read (in sense of constructing a reading of) a manuscript." George E. Marcus e Michael J. Fischer (1986, pp. 30-33) partem dessa metáfora do texto de Geertz para lhe adicionar uma outra: a do diálogo em que o observador participante ou etnógrafo (no caso Ana Maria Amaro), a comunidade que é objeto de estudo (Macau) e o leitor (receptor lusófono) da monografia se devem envolver ao comunicarem com uma cultura-outra. As narrativas partilham ainda características com o chamado romance etnográfico, que definimos em estudos anteriores (PUGA, 2007, p. 175-202; 2009, p. 266) quer como narrativa ficcional produzida com base em resultados de trabalho de campo (etnográfico), sendo utilizados materiais provenientes dessa investigação empírica para caracterizar comunidades ou povos de forma o mais aproximada da realidade possível, quer como um texto ficcional que "cria locais, personagens e ações que o público julga serem autênticos em termos de uma situação cultural, social e política" (FERNEA, 1989, p. 153). Estas duas estratégias de construção do romance etnográfico podem coexistir numa mesma obra, como acontece no conto de que nos ocupamos, pois muitos dos acontecimentos e das práticas culturais representados são facilmente reconhecidos pelo leitor informado, que os associa a referentes do mundo real.

Não são apenas os pregões do padeiro que se fazem ouvir, mas também os ruídos de janelas que se abrem e revelam clientes, as vozes humanas - das crianças seduzidas pelas vitrines transportadas pelos vendedores às mães das primeiras -, e outros sons, aromas e até sabores e paisagens culinárias típicas da Macau histórica. Vejamos, de seguida, de que forma a já referida paisagem simultaneamente acústica e etnográfica veicula as especificidades culturais do território, imagens essas há muito desaparecidas das ruas de Macau. Em trabalhos recentes (PUGA, 2011) definimos imagem sonora como o conjunto de sons 'descritos', sugeridos e/ou reproduzidos num texto literário. O referido conceito foi cunhado por Raymond Murray Schafer (1933-), com base no termo landscape, no âmbito da sua investigação na área da 
ecologia acústica [The New Soundscape (1969), The Soundscape: Our Sonic Environment and the Tuning of the World (1977)], e tem vindo a generalizar-se em diversas áreas do Saber. O termo remete para os elementos sonoros presentes no texto literário, nomeadamente sons humanos (vozes, música, ruídos industriais), naturais (clima e fenómenos naturais) ou animais, entre outros. A soundmark literária, como verificamos neste estudo no que diz respeito à Macau das décadas de (19)60-70, encontra-se associada aos sons típicos de um período numa zona geográfica, como a Macau dos anos (19)60 e 70, e, de acordo com Emily Ann Thompson (2004, p. 1), "like a landscape, a soundscape is simultaneously a physical environment and a way of perceiving that environment". Poderá tratar-se de uma paisagem sonora nacional, local, rural ou urbana, como acontece no conto regional em questão, que mapeia os ruídos e sons (sobretudo chineses) típicos das várias horas do dia num 'burgo' luso-sínica de ambiência algo colonial. De madrugada, o pregão típico do padeiro antecede a "indefinida polifonia diurna" ( $A M$, p. 14) e acorda a população macaense que sai de casa a dialogar em cantonense ("Chou san": bom dia, $A M$, p. 15) para comprar um bem alimentar essencial, fazendo soar portões, enquanto os chinelos de feltro do vendedor "rasgados em ogiva, não soam no asfalto", pelo que este se faz notar nas ruas que percorre apenas pelo seu pregão: "somente a vOz estrídula e gutural se eleva no silêncio, acompanhado pelo ligeiro chocalhar dos vidros das suas duas grandes montras prismáticas, onde os dourados t'im péang, min-pan e siu-kuâi se alinham e se empilham" ( $A M$, p. 14). Bolos doces e salgados são assim empilhados com pão e fazem as delícias de famílias inteiras, cujos membros dialogam entre si e discutem gostos e prioridades. A focalização da narrativa detém-se assim na referida personagem-tipo coletiva, informando a narradora, de forma cinematográfica e dinâmica, que os vendilhões, "na sua maioria mulheres de Argos chapéus de bambu entrelaçado, cestos suspensos de quatro arames fortes, dos delgados colmos de bambu, ou roliças varas de pau preto, gritam os seus pregões, sentando-se, aqui e além, sobre os calcanhares, apregoando de quando em vez". ( $A M$, p. 15). As vielas são ainda percorridas por avós, netos, mães, donas de casa e cules que conduzem ruidosos riquexós, assemelhando-se as descrições da narrativa às conhecidas representações pictóricas do pintor romântico britânico George Chinnery (1774-1852), que residiu em Macau entre 1825 e 1852.

Interessaram-nos sobretudo os enredos sonoros e aromáticos, ou seja, os acontecimentos percepcionados pela audição e pelo olfato das personagens-residentes que escutam paisagens acústicas; daí que R. Murray Schafer (1993, p. 212) utilize a figura do turista a apreciar uma determinada soundscape em busca não dos Sehenswürdigkeiten (objetos com interesse visual), mas sim dos Hörenswürdigkeiten (objetos com interesse auditivo), como se verifica, até certo ponto, com a narradora do conto de que nos ocupamos ao 
descrever a figura-tipo do vendedor, não apenas descrito visual, mas também acusticamente. A soundscape, ou sonografia, enquanto elemento simbólico e estruturante do texto literário, tem, portanto, implicações sociais, estéticas, culturais e políticas ao concorrer quer para a caracterização do espaço (histórico-social/etnográfico) da ação e do sentimento de pertença de determinadas personagens. Os vendilhões nas ruas de Macau produzem pregões específicos que são ouvidos e descodificados por residentes no interior das casas e pelos transeuntes, permitindo-nos analisar de que forma as personagens chinesas ouvem, percepcionam e se relacionam com o mundo que as rodeia. As paisagens auditivas são portanto análogas à paisagem visual, remetendo para a informação geográfica percepcionada em conjunto pela visão e pela audição e ainda pelo olfacto, sensações que, por sua vez, auxiliam o ser humano a localizar-se no espaço. Enquanto a paisagem humanizada e arquitetónica captada pela visão não muda de imediato, cheiros e sons aparecem, mais ou menos intensos, e esbatem-se rapidamente, e, no caso do cheiro, poderá inclusive impregnar-se. No que diz respeito ao mundo natural e até à natureza humanizada, a soundscape é por isso muito mais efémera que a paisagem visual, uma vez que as construções urbanas e as paisagens naturais não mudam repentinamente, como acontece com os sons, à medida que o vendilhão se afasta. Como "Min-Pau-Lou" demonstra, a paisagem sonora também é também percepcionada pelos residentes - que inicialmente não veem (mas apenas ouvem) o vendilhão -, e é uma dimensão importante do quotidiano sobretudo doméstico, essencial para a gestão do lar e dos prazeres das famílias macaenses.

\section{Referências}

AMARO, Ana Maria. Vendilhões Chineses de Macau. Geographica: Revista da Sociedade de Geografia de Lisboa. 4.out.1965, p. 49-62.

AMARO, Ana Maria. Aguarelas de Macau 1960-1970: Cenas de Rua e Histórias de Vida. Um Olhar Retrospectivo, Um Olhar de Saudade. Macau: Comissão Territorial de Macau para a Comemoração dos Descobrimentos Portugueses-Fundação Macau, 1998.

BARREIRA, Ninélio. Ou-Mun: Coisas e Tipos de Macau. Macau: Instituto Cultural de Macau, 1994.

BOTAS, João. Ana Maria Amaro: Macau é uma Recordação Agridoce. Tribuna de Macau. n. 3356, 8.jan.2010, p. 8.

FERNEA, Elizabeth. The Case of Sitt Marie Rose: An Ethnographic Novel from the Modern East. In: Philip A. Dennis e Wendell Aycock (eds.). Literature and Anthropology. Lubbock: Texas Tech University Press, 1989. GEERTZ, Clifford. The Interpretation of Cultures: Selected Essays. Londres: Fontana Press, 1990. 
GOMES, Luís Gonzaga. Chinesices. Macau: Instituto Cultural de Macau, 1994.

MARCUS, George E.; FISCHER, Michael J. Anthropology as Cultural Critique: An Experimental Moment in the Human Sciences. Chicago: The University of Chicago Press, 1986.

MORAES, Wenceslau de. Traços do Extremo Oriente. Siam-China-Japão. Lisboa: Livraria Barateira, 1946.

NUNES, Isabel. Vendilhões de Macau. Macau: ICM, 1998.

PUGA, Rogério Miguel. City of Broken Promises enquanto Romance Etnográfico: Representações da Macau Setecentista. Polissema: Revista de Letras do ISCAP 7 (2007), p. 175-202.

A World of Euphemism: Representações de Macau na Obra de Austin Coates: City of Broken Promises enquanto Romance Histórico e Bildungsroman Feminino. Lisboa: Fundação para a Ciência e a TecnologiaMinistério da Ciência, Tecnologia e Ensino Superior/Fundação Calouste Gulbenkian, 2009.

- Soundscape. In: CEIA, Carlos (ed.). E-Dicionário de Termos Literários (www.edtl.com.pt), 2011. Acesso em: 20.jan.2012.

REGO, Francisco de Carvalho e. Cartas da China. Macau: Imprensa Nacional, 1949.

SCHAFER, R. Murray. The Soundscape: Our Sonic Environment and the Tuning of the World. Rochester: Destiny Books, 1993.

THOMPSON, Emily Ann. The Soundscape of Modernity: Architectural Acoustics and the Culture of Listening in America, 1900-1933. Cumberland: MIT Press, 2004. 